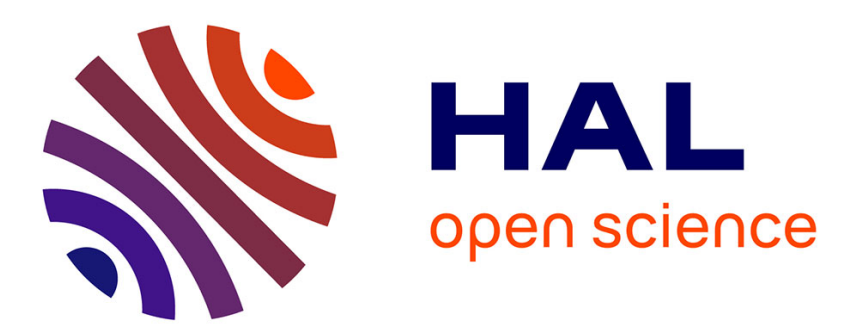

\title{
Decentralized robust control-system for a non-square MIMO system, the air-path of a turbocharged Diesel engine
}

Abderrahim Lamara, Guillaume Colin, Patrick Lanusse, Yann Chamaillard, Alain Charlet

\section{To cite this version:}

Abderrahim Lamara, Guillaume Colin, Patrick Lanusse, Yann Chamaillard, Alain Charlet. Decentralized robust control-system for a non-square MIMO system, the air-path of a turbocharged Diesel engine. 2012 IFAC Workshop on Engine and Powertrain Control, Simulation and Modeling (ECOSM), Oct 2012, Rueil-Malmaison, France. hal-00767698

\section{HAL Id: hal-00767698 \\ https://hal.science/hal-00767698}

Submitted on 20 Dec 2012

HAL is a multi-disciplinary open access archive for the deposit and dissemination of scientific research documents, whether they are published or not. The documents may come from teaching and research institutions in France or abroad, or from public or private research centers.
L'archive ouverte pluridisciplinaire HAL, est destinée au dépôt et à la diffusion de documents scientifiques de niveau recherche, publiés ou non, émanant des établissements d'enseignement et de recherche français ou étrangers, des laboratoires publics ou privés. 


\title{
Decentralized robust control-system for a non-square MIMO system, the air-path of a turbocharged Diesel engine
}

\author{
Abderrahim LAMARA ${ }^{* * *}$, Guillaume COLIN*, Patrick LANUSSE**, Yann CHAMAILLARD*, Alain Charlet* \\ * University of Orléans, PRISME, EA4229 \\ 8, rue Léonard de Vinci, 45072 Orléans, France \\ Tel : +33(0) 238494 365, yann.chamaillard@univ-orleans.fr \\ Tel : +33(0) 238494 514, guillaume.colin@univ-orleans.fr \\ Tel : +33(0) 238494839 alain.charlet@univ-orleans.fr \\ ** University of Bordeaux, IPB, IMS CNRS UMR5218 \\ 351 cours de la libération, 33405 Talence, France \\ Tel : +33(0) 663488 442, abderrahim.lamara@d2t.fr \\ Tel : +33(0) 540002417 patrick.lanusse@ims-bordeaux.fr
}

\begin{abstract}
The targeted purpose here is the control of a nonlinear and non-square system with three inputs and two outputs in order to reduce soot and greenhouse gas pollutants. In this paper, a non-square multivariable controller for the air-path system of a turbocharged Diesel engine is proposed. The controller is designed using the CRONE (Commande Robuste d'Ordre Non Entier) Control-System-Design approach to maintain performance and robust stability for a wide set of operating points. In this research, we focused on the multi-input multi-output system identification problem, and test-bench data were processed to find a nominal linear model. The controller was then designed via an open-loop transfer function optimization. Finally, simulation results from a simulation model show the performance of the proposed control-system.
\end{abstract}

Keywords: Diesel engine air path, Robust control, CRONE, Multivariable control, Non-square system.

\section{I - INTRODUCTION}

With increasing environmental concerns and ever stricter emission standards [Michael, M. and Walsh, P., 2000], current Diesel engine control research focuses on simultaneous Soot and Nitrogen Oxides (NOx) reduction, while maintaining reasonable fuel economy and drivability.

Improvements in the air system control can succeed in meeting stricter emission regulations and customer demands. The hardware component of Exhaust Gas Recirculation (EGR), integrated in the air path system, complicates the engine configuration. This advanced hardware component may result in significant nonlinearities and interactions [Wang, Y. et al, 2011] [Larsen, M. et al, 2003], so that advanced control methods are required. Usually EGR, throttle (Th) and turbocharger valves (Wastegate, WG) are used as actuators (inputs) to ensure boost or manifold pressure and air flow (output) as shown on figure 1.

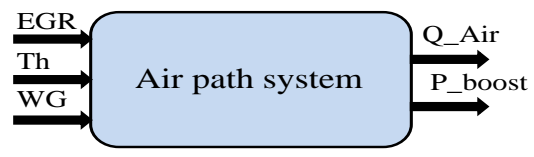

Fig. 1.1: Air path system representation.

In the literature, different approaches have been proposed for this Diesel engine control problem. In [Alberer, D. et al, 2010] a virtual reference design approach was used to evaluate the choice of actuators, before applying the method to the fuel path and air path subsystems. The virtual variables can be seen as local mappings of the target variables onto an input space, and provide a valuable insight into the contribution of the different input quantities [Alberer, D. et al, 2010].

Most recent Diesel engine control research uses a physical model [Leroy, T. et al, 2010] [Chauvin J. et al, 2008] [Stefanopoulou, A.G. et al] to simulate controller efficiency, before testing the controller performance and robustness on a test bench. In [Kocher, L. et al, 2011], a reduced order model of the air handling system of a modern diesel engine was developed based on physical equations. This model-based control is intended for the development of the closed-loop control and estimation strategy.

The tuning, however, is often based on ad-hoc trial and error methods. In [Chauvin, J. et al, 2006] [Larsen, M. et $a l, 2003]$ an open-loop control law was applied as a feedforward, to control both intake manifold pressure and exhaust pressure. An estimator was also proposed to estimate the measurements which are not available, in order to ensure the closed-loop control. A coordinated passivation design in [Kocher, L. et al, 2003] was applied to control a simplified third-order engine model. [Murilo, A. et al, 2011] proposed a multivariable control strategy based on a parameterized nonlinear model predictive control approach. Nonlinear continuous-time generalized predictive control was presented in [Dabo, M. et al, 2008] [Garcia-Nieto, S et 
al, 2008] and a model-based Quantitative Feedback Theory control in [Wang, Y. et al. 2008].

Most works presented above use not the throttle as a third actuator. As in [Colin, G. et al, 2011] a Multi-SISO robust CRONE design was proposed to control both EGR and wastegate (WG) valves. Here we extend [Colin, G. et al, 2011] and the throttle valve (Th) will be taken into account.

The paper is organized as follows. In section II, system description, identification and the physical model are presented. Section III gives, an introduction to the CRONE MIMO approach is proposed. Section IV addresses the open-loop optimization and the design of a decentralized controller. In the last section, results are shown and discussed.

\section{II - SYSTEM DESCRIPTION}

The system is a 4 cylinders with $2.0 \mathrm{~L}$ turbocharger Diesel Engine, and $80.9 \mathrm{KW}$. The three air path actuators, that is wastegate (WG), EGR valve (EGR) and intake throttle (Th) are pneumatic (use compressed air). The air path system of the turbocharged Diesel engine is described by Fig. 2.1.

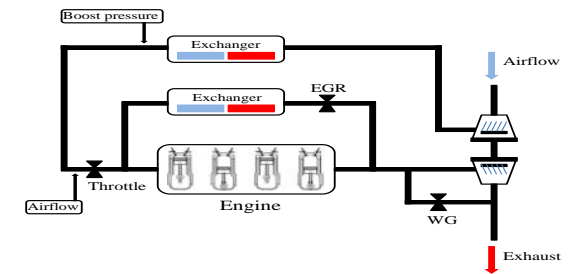

Fig. 2.1: Air path scheme of a turbocharged Diesel engine with Exhaust Gas Recirculation (EGR).

The fresh air coming from the atmosphere is compressed and warmed up by compressor. The exchanger cools it down which increase the density of flow $\left(Q_{\text {air }}\right)$ and decreasing the boost pressure $\left(p_{\text {boost }}\right)$. The throttle valve (Th) controls the flow before the intake and EGR system. The mixture of intake flow and exhaust flow decreases the mean combustion temperature and reduces $\mathrm{NO}_{\mathrm{x}}$ production, but at the same time it decreases engine efficiency. In the end of combustion, a part of the burned gases can be recirculated through the EGR valve and cooled down by the EGR cooler. The exhaust flow can also flow through the turbine, and speed it up. This energy is transmitted by a shaft to the compressor which adjusts the boost pressure. The turbine speed can be tuned by adjusting the wastegate (WG) position. Finally the exhaust gas returns to the atmosphere.

\section{II.1 System-Identification}

Complex plant structures often require complex technologies to meet performance requirements. Robust control can be used to achieve high levels of disturbance rejection. The CRONE approach requires to models the frequency response of the system around its different possible operating points. The frequency-domain identification of the linear dynamic model of the air path (which is a non-minimum phase and MIMO system) could be achieved using various excitation signals including random noise, burst random noise, pulse-impact, multisine [Jesse, B. et al, 2006] [Thomas, J. et al, 2008] [Colin, G. et al 2011], and chirp and pseudo-random binary (PRBS) [Wang, Y. et al, 2011] signals.

The goal of frequency domain system identification is to obtain a linear time-invariant model that approximates the dynamics of an unknown plant. Generally, the plant may have nonlinear time-varying dynamics. Plant nonlinearities often induce harmonic responses to sinusoidal input signals [Jesse, B., et al, 2006].

A multisine excitation signal is used here to identify the air path system. The use of this broadband signal allows faster frequency domain identification. The choice of operating points for air path system identification (green cross in Fig. 2.2) is based on the high pollutant area (pink area in Fig. 2.2), where The EGR flow can reduce NOx production.

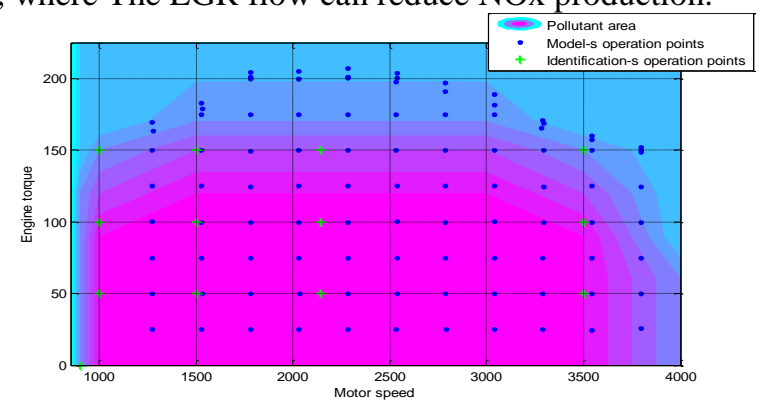

Fig. 2.2: All the operating points used for system identification and model building.

\section{II.2 Identification process}

The identification step requires multisine signal specifications. This signal is a linear combination of sinusoids which is often given by:

$$
u(t)=\sum_{k=1}^{N} A_{k} \cos \left(2 \pi f_{k} t+\varphi_{k}\right)
$$

where $N$ is the number of harmonics in the signal, $f_{k}$ is a harmonic frequency, $A_{k}$ is a harmonic amplitude, and $\varphi_{k}$ is the initial phase of each harmonic.

The amplitude $A_{k}$ is chosen in such way that system remains at the same operating point during identification, and also gives a linear response. Frequencies are selected to provide enough information about system dynamics within a given frequency range.
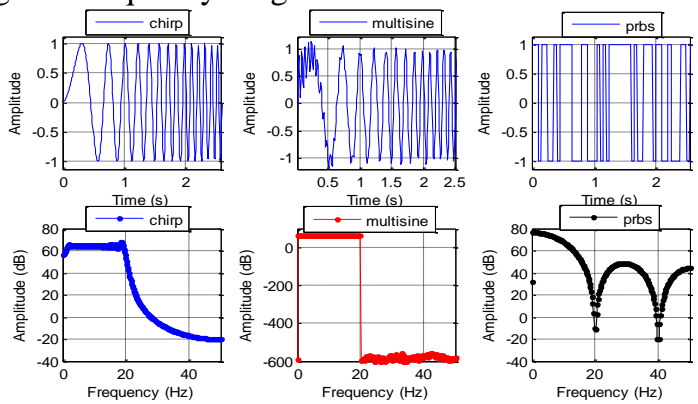

Fig. 2.3: Time and frequency responses comparison for different excitation signals. 
Fig. 2.3 compares the frequency responses of chirp, multisine and PRBS signals. It can be seen that all the frequency response of the multisine signal is inside the window defined by the signal frequencies specifications. With chirp and PRBS, part of the frequency response is outside the window defined by the signal frequencies specifications.

Those frequencies $f_{k}$ are chosen such that the timeinvariant nominal model approximates the most important linear dynamics of the real system. The max frequency $f_{N}$ must be greater than the desired cut-off frequency of the system. To design a controller $f_{N}$ must be at least ten times larger than the required frequency bandwidth given by the disturbance rejection specifications.

The identification of each element of the transfer matrix consists in exciting only one input, and each element of the matrix is calculated using the Fourier transform (FFT) of the ratio of the cross-correlation between output and input $\tau_{y x}$ divided by the autocorrelation of the input $\tau_{x x}$ :

$$
G=\frac{\left.F F T\left(\tau_{y x} \text { (output, } \text { input }\right)\right)}{F F T\left(\tau_{x x}(\text { input }, \text { input })\right)}
$$

Each input-output transfer is then described:

$\boldsymbol{G}_{\mathbf{1 1}}$ : from EGR (\%) valve to airflow sensor $(\mathrm{g} / \mathrm{s})$

$\boldsymbol{G}_{12}$ : from Th valve (\%) to airflow sensor $(\mathrm{g} / \mathrm{s})$

$\boldsymbol{G}_{\mathbf{1 3}}$ : from WG $(\%)$ valve to airflow sensor $(\mathrm{g} / \mathrm{s})$

$\boldsymbol{G}_{\mathbf{2 1}}$ : from EGR (\%) valve to boost pressure sensor (bar)

$\boldsymbol{G}_{\mathbf{2} 2}$ : from Th valve (\%) to boost pressure sensor (bar)

$\boldsymbol{G}_{\mathbf{2 3}}$ : from WG valve (\%) to boost pressure sensor (bar)

The signal excitation was chosen with a sampling frequency at $1 \mathrm{kHz}$, a frequency range from 0.1 to $20 \mathrm{~Hz}$ and contains 200 frequencies. Fig. 2.4 presents the Bode diagram computed from (2). A triangular window was used to reduce the noise effect. Despite the use of windowing the noise effect is still important. The noise problem will be discussed in section III.

As multisine frequency domain identification provides a non-parametric model, second order with delay transfer functions are used to obtain a nominal parametric model of the plant:

$$
G_{i j}=\frac{A}{\left(s+b_{0}\right)\left(s+b_{1}\right)} e^{-\tau s}
$$

As shown on Fig. 2.4, the nominal plant (black curve) is defined from the average gains and phases. The nominal transfer function matrix expression is given by:

$$
\left[\begin{array}{lll}
-\frac{2771.69}{(s+45)(s+19)} e^{-0.033 s} & -\frac{1331.31}{(s+14)(s+60)} e^{-0.026 s} & \frac{188.6}{(s+17)(s+7)} e^{-0.44 s} \\
\frac{1928.22}{(s+64)(s+15.1)} e^{-0.003 s} & -\frac{1397.03}{(s+42.8)(s+14.8)} e^{-0.11 s} & \frac{100.23}{(s+20)(s+1)} e^{-0.55 s}
\end{array}\right]
$$
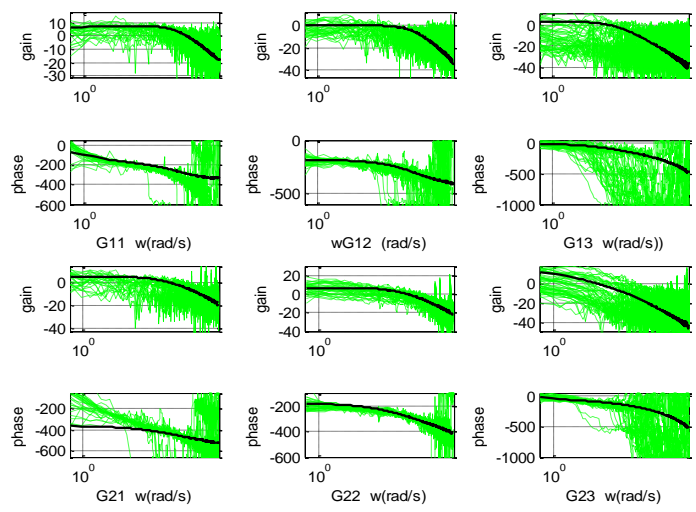

Fig. 2.4: Bode diagram of nominal plant frequency response (solid black curve) and all operating point frequency responses (green curves).

\section{III - MIMO CRONE DESIGN METHODOLOGY}

The CRONE control-system design methodology is a frequency-domain approach that has been used since the eighties [Oustaloup, A. et al., 1983, 1991, 1995; Lanusse, P. et al, 1994, 2005; Åström, K.J. 1999].

The objective of the CRONE control system design is to robustify the closed loop dynamic performance through either a robust damping factor, or a robust resonant peak control based on the unity-feedback configuration (Fig. $3.1)$.

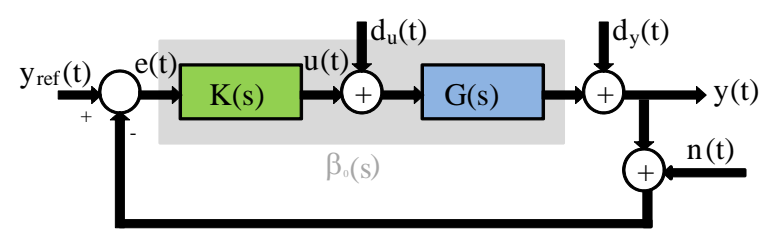

Fig. 3.1: Unity-feedback configuration for CRONE approach.

The aim of the CRONE MIMO design is to find a diagonal open-loop transfer matrix. Each element is defined by a fractional order transfer function. Fractional differentiation is used to define the nominal and optimal open-loop:

$$
\beta_{0}(s)=G_{0}(s) K(s)
$$

For non-square systems [Nelson Gruel, D. et al, 2008, 2009], the optimization of $\beta_{0}$ makes it possible to calculate the controller which is given by the expression.

$$
K(s)=G_{0}^{\dagger}(s) \beta_{0}(s)
$$

where $G_{0}^{\dagger}(s)$ is the Moore-Penrose pseudo-inverse of nominal plant $G_{0}(s)$. Moore and Penrose show that a solution can exist for the equation $b=A y$ where $b \in C^{m}$ and $y \in C^{n}$ and $A \in C^{m x n}$. Using Graybill's theorem [Graybill, F.A., 1969] the matrix $A_{0}^{\dagger}$ of rank $r$ can be calculated as:

$$
\forall m>n \Rightarrow \exists A^{\dagger}
$$


where $A^{\dagger}=A^{H}$. $\left(A A^{H}\right)^{-1}$ and $A A^{\dagger}=I_{m x n}$

$\forall n>m \Rightarrow A^{\dagger}=\left(A A^{H}\right)^{-1} \cdot A^{H}$ and $A^{\dagger} A=I_{n x m}$

where $A^{H}$ is the Hermitian transpose of $A$.

$$
\text { Let } \begin{aligned}
G_{0}(s)= & {\left[\begin{array}{ccc}
g_{11}(s) & \cdots & g_{1 n}(s) \\
\vdots & \ddots & \vdots \\
g_{m 1}(s) & \cdots & g_{m n}(s)
\end{array}\right] } \\
& / g_{i j}(s)=h_{i j}(s) e^{-L_{i j} s}
\end{aligned}
$$

- $\quad h_{i j}(s)$ : is a strictly proper time-delay free transfer function,

Then

$$
G_{0}^{\dagger}(s)=P(s)=\left[\begin{array}{ccc}
P_{11}(s) e^{\gamma_{11} s} & \cdots & P_{1 n}(s) e^{\gamma_{1 n} s} \\
\vdots & \ddots & \vdots \\
P_{m 1}(s) e^{\gamma_{m 1} s} & \cdots & P_{m n}(s) e^{\gamma_{m n} s}
\end{array}\right]
$$

where $P(s)$ is the non-zero polynomial of $s$ with timedelay, and $\gamma_{i j} \in \mathbb{R}^{*+}$.

Each element of the diagonal open-loop matrix is based on the third generation CRONE single-input single-output (SISO) methodology, the principle of this methodology is to optimize the parameters of a nominal open-loop transfer function $\beta_{0}(s)$ that includes a band-limited complex fractional order integration over a frequency range $\left[\omega_{A}, \omega_{B}\right]$. The complex fractional order, $n=a+\mathrm{i} b$ enables a straight line of any direction to be created in the Nichols chart which is called the generalized template (Fig. 3.3).

The SISO nominal open loop transfer function is defined by:

$$
\beta_{0}=\beta_{\mathrm{l}}(s) \beta_{\mathrm{m}}(s) \beta_{\mathrm{h}}(s)
$$

- where $\beta_{\mathrm{m}}(s)$ is a set of band-limited generalized templates:

- where

$$
\beta_{\mathrm{m}}(s)=\prod_{k=-N^{-}}^{N^{+}} \beta_{\mathrm{m} k}(s)
$$

with:

$$
\begin{aligned}
& \beta_{\mathrm{m} k}(s) \\
& =C_{k}^{\operatorname{sign}\left(b_{k}\right)}\left(\alpha_{k} \frac{1+\frac{s}{\omega_{k+1}}}{1+\frac{s}{\omega_{k}}}\right)^{a_{k}}\left(\Re e_{/ i}\left\{\left(\alpha_{k} \frac{1+\frac{s}{\omega_{k+1}}}{1+\frac{s}{\omega_{k}}}\right)^{i b_{k}}\right\}\right)^{-q_{k} \operatorname{sign}\left(b_{k}\right)} \\
& \alpha_{k}=\left(\frac{\omega_{k+1}}{\omega_{k}}\right)^{1 / 2} \text { for } k \neq 0 \text { and } \alpha_{0}=\left(\frac{1+\left(\frac{\omega_{\mathrm{r}}}{\omega_{0}}\right)^{2}}{1+\left(\frac{\omega_{\mathrm{r}}}{\omega_{1}}\right)^{2}}\right)^{\frac{1}{2}}
\end{aligned}
$$

where $\beta_{1}(s)$ is an integer order $n_{1}$ proportional integrator

$$
\beta_{\mathrm{l}}(s)=C_{\mathrm{l}}\left(\frac{\omega_{-N^{-}}}{s}+1\right)^{n_{\mathrm{l}}}
$$

- where $\beta_{\mathrm{h}}(s)$ is the low-pass filter of integer $n_{\mathrm{h}}$

$$
\beta_{\mathrm{h}}(s)=C_{\mathrm{h}}\left(\frac{s}{\omega_{N^{+}}}+1\right)^{n_{\mathrm{h}}}
$$

The gains $C_{k}, C_{\mathrm{l}}$ and $C_{\mathrm{h}}$ are such that $\omega_{\mathrm{r}}$ is the closed-loop resonant frequency. Order $n_{1}$ has to be set to manage the accuracy provided by the control-system. Order $n_{\mathrm{h}}$ has to be set to obtain a proper or bi-proper control-system. When useful, $N^{-}$and $N^{+}$are different from 0 to increase the number of tuning parameters used for the open-loop shaping.

For time-delay, non-minimum phase or unstable SISO systems, the open-loop transfer function must include the nominal time-delay and right half plane zeros and poles of $G_{0}$ to make the controller achievable and the closed loop fully stable [Lanusse, P. et al, 1994, 2005].
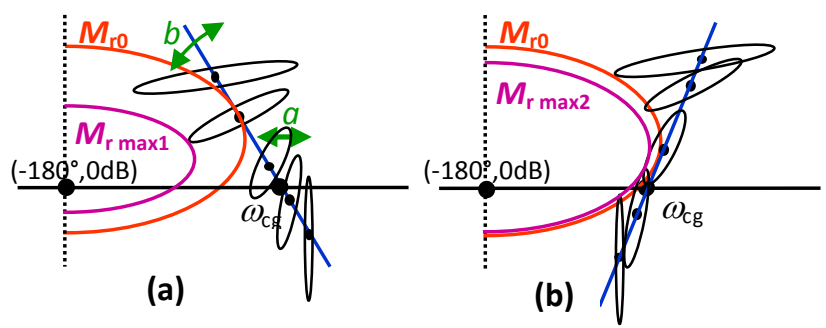

Fig. 3.3: (a) any generalized template, (b) optimal template as $M_{\mathrm{r} \max 2}$ (maximum resonant peak) is closer to $M_{\mathrm{r} 0}$ than $M_{\mathrm{r}}$ $\max 1$ is.

The optimal approach allowed by the generalized template ensures an optimal positioning of the frequency uncertainty domains (Fig. 3.3) which reduce the resonant peak $M_{\mathrm{r}}$ variations (strongly correlated to overshoot variations) of the complementary sensitivity function $T(s)$. The robustness cost function is given by:

$$
J=\left(M_{\mathrm{r}_{0}}-\inf \left|M_{\mathrm{r}}\right|\right)^{2}+\left(\sup \left|M_{\mathrm{r}}\right|-M_{\mathrm{r}_{0}}\right)^{2}
$$

where $M_{\mathrm{r}_{0}}$ is the nominal value of the resonant peak. Its minimization is accomplished while respecting closed loop constraints for all plants $G$ and for $\omega \in \mathbb{R}^{+}$.

$$
\begin{aligned}
& \inf |T(j \omega)| \geq T_{1}(\omega), \sup |T(j \omega)| \leq T_{\mathrm{u}}(\omega), \\
& \sup |S(j \omega)| \leq S_{\mathrm{u}}(\omega), \sup |K S(j \omega)| \leq K S_{\mathrm{u}}(\omega), \\
& \sup |G S(j \omega)| \leq G S_{\mathrm{u}}(\omega),
\end{aligned}
$$

with $\left\{\begin{array}{rlrl}T(s) & =\frac{G(s) K(s)}{1+G(s) K(s)} & & S(s)=\frac{1}{1+G(s) K(s)} \\ K S(s) & =\frac{K(s)}{1+G(s) K} & G S(s)=\frac{G(s)}{1+G(s) K(s)}\end{array}\right.$

The frequency uncertainty domains are defined from the multiplicative uncertainty of the open-loop frequency response in the Nichols chart. This multiplicative uncertainty is invariant and equal to the plant uncertainty:

$$
\beta(s)=G(s) K(s)=G_{0}(s) \Delta_{\mathrm{m}} K(s)=\beta_{0}(s) \Delta_{\mathrm{m}}
$$

where $G_{0}$ and $\beta_{0}$ are the nominal plant and open-loop transfer function, and where $\Delta_{\mathrm{m}}$ is the multiplicative uncertainty model.

For MIMO systems, the resonant peaks taken into account in the cost function to be minimized are those of the diagonal elements of the perturbed values (not only the 
nominal one) of the complementary sensitivity transfer function matrix and the controller elements are obtained from relations (5) and (7):

$$
K_{i j}(\mathrm{j} \omega)=P_{i j}(\mathrm{j} \omega) e^{\gamma_{i j} \mathrm{j} \omega} \beta_{j j}(\mathrm{j} \omega)
$$

As $\beta_{j j}(s)$ are fractional order transfer functions, the rational transfer functions $K_{\mathrm{R} i j}(s)$ are obtained by identifying the ideal frequency responses $K_{i j}(\mathrm{j} \omega)$ by low-order transfer functions:

$$
K_{\mathrm{R}_{i j}}(s)=\frac{B(s)}{A(s)}
$$

where $B(s)$ and $A(s)$ are polynomials of specified integer degrees $n_{\mathrm{B}}$ and $n_{\mathrm{A}}$. All the frequency-domain systemidentification techniques can be used [Oustaloup, A. et al, $2000,2002]$. Whatever the complexity of the control problem, it is easy to find satisfactory values of $n_{\mathrm{B}}$ and $n_{\mathrm{A}}$ generally about 6 without a reduction in performance.

\section{IV - DESIGN OF A DECENTRALIZED CRONE CONTROLLER}

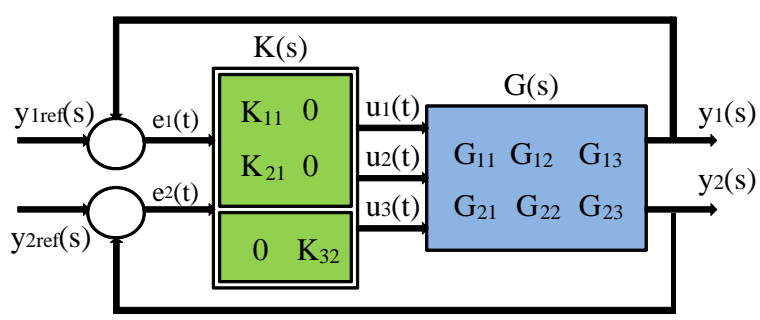

Fig. 4.1: Decentralized control of a 3x2 MIMO plant.

For non-square systems, the Block Relative Gain (BRG) array method [Kariwala, V. et al., 2003; Jesse B, et al, 2006] is used to evaluate different block interactions. A system is weakly interacting if BRG is close to the identity matrix. If the singular values of the BRG are very different from unity, the closed-loop system has large interactions. Thus the BRG method is used to allocate inputs to outputs. Then to simplify the use of the proposed MIMO methodology, all the blocks with a weak BRG are assumed equal to zero and a new nominal plant $G_{0}^{\prime}$ is defined:

$$
G_{0}^{\prime}=\left[\begin{array}{ccc}
G_{11} & G_{12} & 0 \\
0 & 0 & G_{23}
\end{array}\right]
$$

From (5) the controller will be a decentralized controller. However the elements of the nominal (and diagonal) open loop transfer function matrix are optimized by taking into account the full MIMO transfer function frequency response defined by $G$ (Fig. 2.4). As shown by Fig. 2.4, the computed phase of $G_{23}$ is very uncertain and would prevent a good optimization of the nominal open loop transfer function. Here an example of identification of a known transfer function $H(s)=\frac{1}{s^{2}+s+1}$ using a triangular window is performed. As shown by Fig. 4.2, the phase (blue curve) differs from the true phase from $16 \mathrm{rad} / \mathrm{s}$.
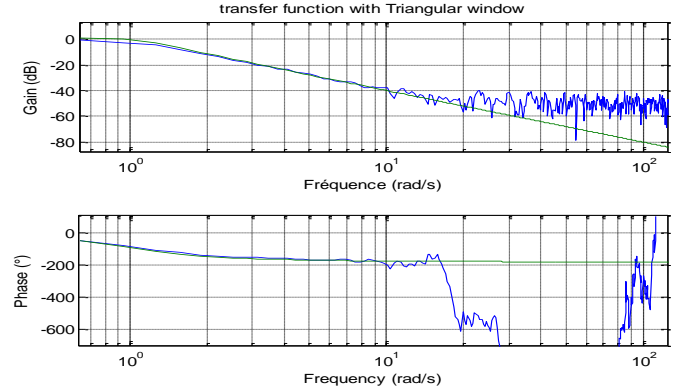

Fig. 4.2: Identification of a known transfer function (green) using a triangular window.

This phenomenon can be explained by the existence of numerical noise. Thus, the corrupted phase of $G_{23}$ was approximated with a shifted phase which has the same appearence as the nominal plant phase (Fig. 4.3).
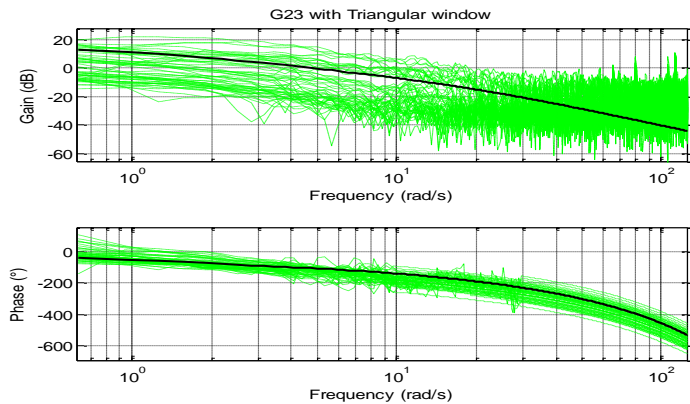

Fig. 4.3: Bode diagram of the new template of the frequency response.

Taking into account this corrected phase, the equivalent open loop frequency responses (computed from the perturbed frequency response of the diagonal elements of the complementary sensitivity transfer function) are not uncertain in the extreme and optimization of the parameters of nominal $\beta_{10}(s)$ and $\beta_{20}(s)$ is achievable.
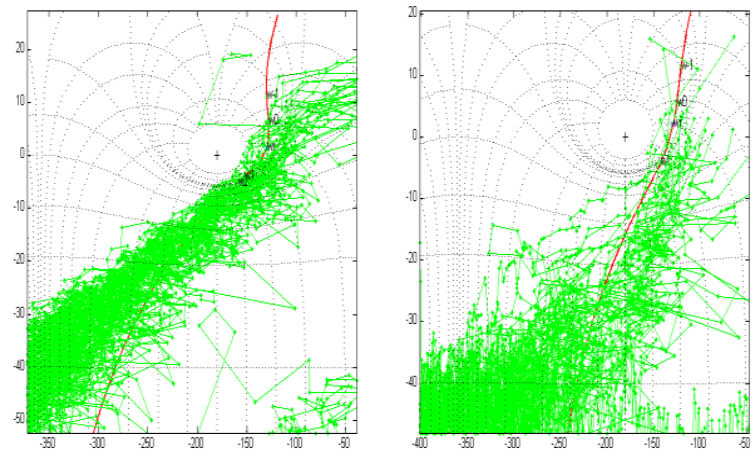

Fig. 4.4: Optimization of open-loop $\beta_{1}(s)$ (for air flow control - left) and $\beta_{2}(s)$ (for boost pressure control - right). Fig. 4.4 presents the nominal optimized open loop frequency responses (red). The multiplicative uncertainty (green) resulting from all the perturbed equivalent openloop frequency responses has been placed outside the low stability area of the Nichols chart.

In this work, the set of specifications was not fully defined, so the optimal specifications are required in order to find the best general template position. Fig. 4.5 and Fig. 4.6 present the closed loop sensitivity functions $T(s)$ and $K S(s)$. 
The greatest values of the diagonal element of $T$ are 1.99 for $T_{11}$ and 2.1 for $T_{22}$.
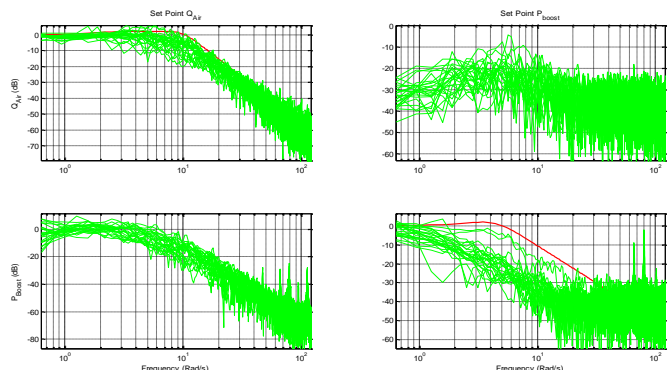

Fig. 4.5: Complementary sensitivity function $T(s)$.
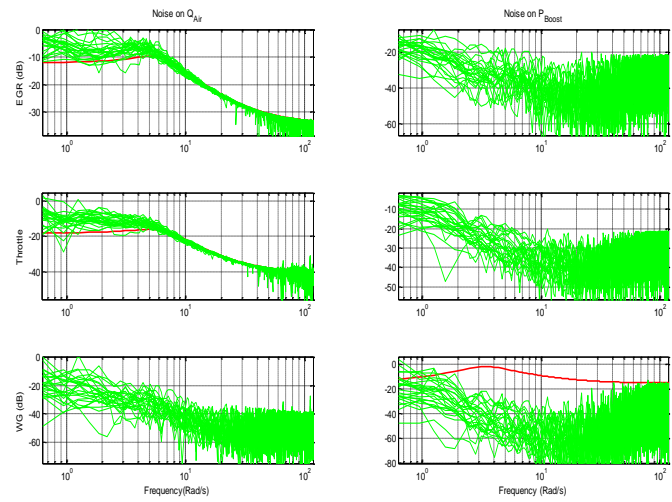

Fig. 4.5: Sensitivity function $K S(s)$.

From the complementary sensitivity function $T_{21}$, we can note that each $1 \mathrm{mbar}$ could generate a noise of $0.1 \mathrm{~g} / \mathrm{s}$ at the airflow output. Also from $\mathrm{T}_{12}$, each $1 \mathrm{~g} / \mathrm{s}$ could generate a noise of 0.3 mbar at the boost pressure output. So $Q_{A i r}$ could be more affected by $P_{\text {Boost }}$ pressure, than $P_{\text {Boost }}$ could be affected by $Q_{\text {Air }}$.

As explained in section III, low order rational transfer functions were used to approximate the desired frequency response of each element of the decentralized controller:

$$
\left\{\begin{array}{c}
K_{11}(s)=\frac{-14.3\left(s^{3}+11.5 s^{2}+48.3 s+1.5\right)}{s^{5}+25.9 s^{4}+229.6 s^{3}+796.2 s^{2}+484.6 s} \\
K_{21}(s)=\frac{-7.9\left(s^{3}+12.2 s^{2}+54.2 s+80.6\right)}{s^{5}+27.2 s^{4}+268.2 s^{3}+1023 s^{2}+635.9 s} \\
K_{31}(s)=\frac{1.2\left(s^{3}+7.1 s^{2}+15.1 s+9.1\right)}{s^{4}+15.4 s^{3}+62.1 s^{2}+51.67 s} \\
\text { V - SIMULATION RESULTS }
\end{array}\right.
$$

In this section, only simulation results are presented. Indeed, the controller was tested before on the linear nominal plant controller performance hence, using the simulation physical (nonlinear) model, the controller is assessed in several operating points in order to check controller performance and robustness.

\section{V-1 Anti wind up problem}

In order to include an anti-windup strategy in the controller, each element of (17) is written:

$$
K_{i j}(s)=K_{i j}^{\prime}(s)\left(1+\frac{\alpha_{i j}}{s}\right)
$$

Using a model of the system saturation and a gain, Fig. 5.1 shows how the integrator part is fed back to manage the actuators saturation problem.

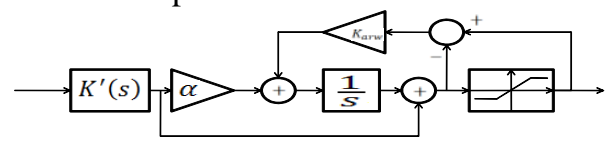

Fig. 5.1: Anti-windup controller with feedback gain.

\section{V.2 Simulation}

The simulation model is based on physical equations and on look-up tables. It was calibrated with engine test bench results. The controller was tested with this nonlinear model which is able to simulate the motor behavior on 96 operating points (blue points on Fig. 2.2). As the AMEsim model can be integrated in a real-time target, it allows us to run a real time simulation. The other advantage of AMEsim is the co-simulation with Simulink, which means that the AMEsim simulation results can be analyzed using the Matlab workspace.

As explained by section II.3 the model has been calibrated with our engine test bench results. In such way it gives the same mean values and a close dynamical behavior of the real engine. A particular attention has been payed for actuator dynamics. The simulation model allows us to assess the controller performance in several operating points (different values of torque and engine speed). Fig. 5.2 and Fig. 5.3 show, respectively, the system response and valves positions. In this test a speed at 3000rpm has been chosen, with torque variation from $50 \mathrm{Nm}$ to $100 \mathrm{Nm}$, and from $100 \mathrm{Nm}$ to $150 \mathrm{Nm}$.
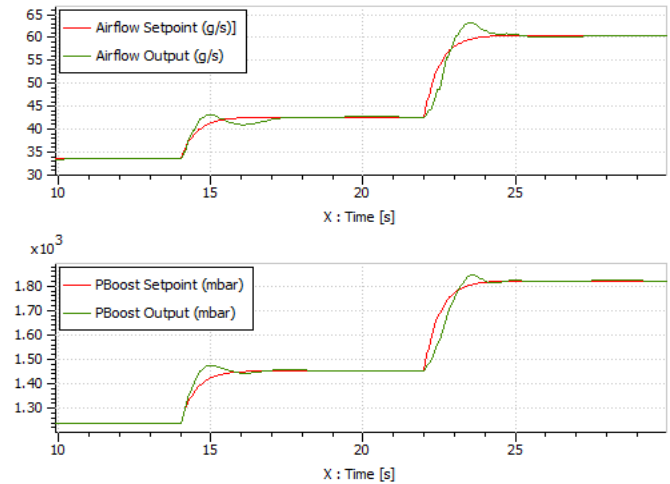

Fig. 5.2: Airflow and boost pressure response in simulation.

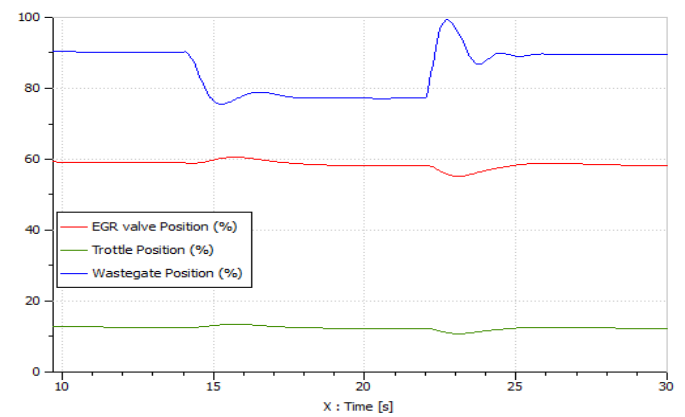

Fig. 5.3: Valve positions in simulation. 
Fig. 5.2 presents both $\mathrm{Q}_{\text {air }}$ and $\mathrm{p}_{\text {boost }}$ responses (closed loop response). The setpoints (red curves) have been filtered by a low-pass filter with a time constant of $0.5 \mathrm{~s}$. Despite of filtering one can note an overshoot of airflow at $23 \mathrm{~s}$ due to $\mathrm{p}_{\text {boost }}$ influence (see T sensitivity). Fig. 5.3 shows engine's valves positions, the wastegate variation appears more important comparing with the others valves, which can explains the influence of the $\mathrm{p}_{\text {boost }}$ on the $\mathrm{Q}_{\text {air }}$ outputs. The used filter can cause a setpoint tracking problem during driving [Dabo,K et al. 2009]. On Fig. 5.4, co-simulation results on a short part of the European driving cycle are shown in order to check controller tracking performances.
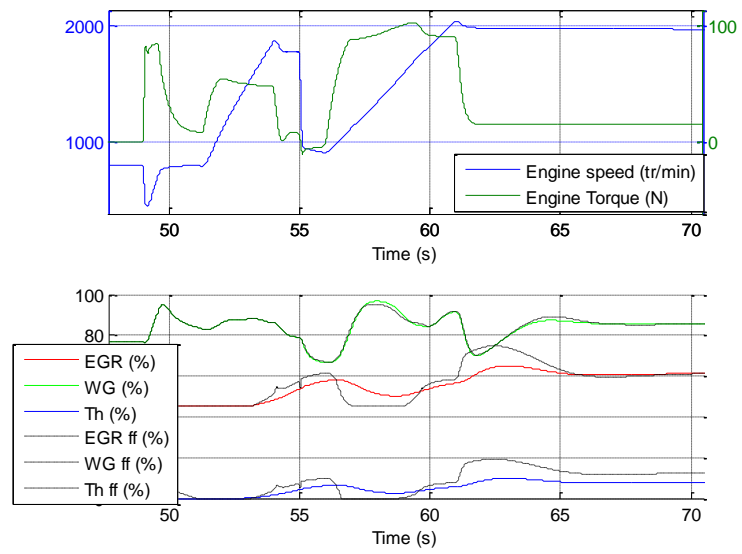

Fig. 5.4: Driving cycle engine torque, engine speed set points and input effort on co-simulation.
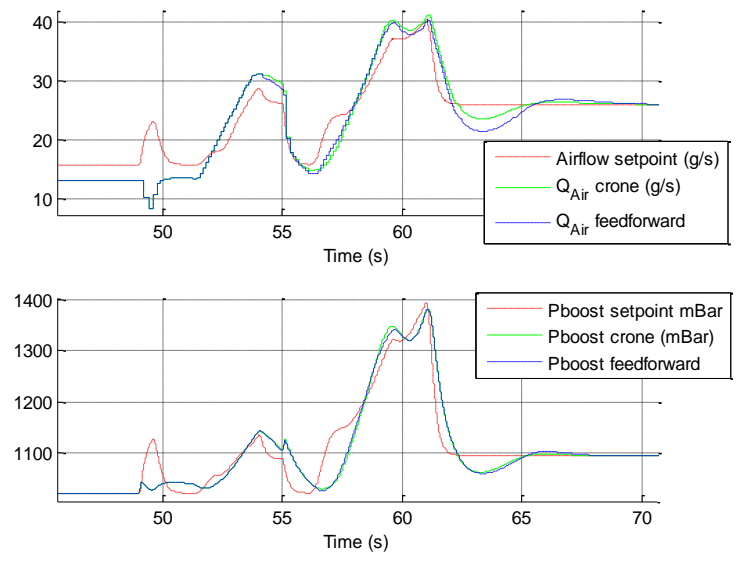

Fig. 5.5: Airflow and boost pressure responses on cosimulation.

Fig. 5.4 shows engine torque and engine speed operating points. Based on this two coordinates, the airflow and boost pressure set-points are generated automatically from a lookup table to set the engine operating point.

Two responses are drawn (Fig. 5.5) in order to compare the CRONE controller performance with and without feedforward, it (Fig. 5.5) presents the airflow and boost pressure reference tracking. In co-simulation, a filter with time constant of $0.2 \mathrm{~s}$ is used here to filter the sharp variation of the set point.

Respectively the curves in green and blue, where one note in the rising phase, the controller performs better with feedforward. Contrary in the falling phase, the controller without feedforward performs better. As shown on airflow response, at time 64s, the green curve undershoot is less than the blue one. From Fig. 5.4 both EGR and Throttle valves need more effort to be controlled, which can reduce valves life and consume much energy. From the Fig. 5.3 and Fig. 5.4 (crone) at 60 s and 70 s, one note that the controller, with and without feed-forward, gives different mean values of the throttle position, which agree with our case, number of inputs greater than outputs.

The decentralized non square CRONE approach allows us to control the airpath of a Diesel engine with three pneumatic actuators and two sensors only. Despite the change of the operating point (Fig. 5.4, engine speed and engine torque) the controller tracks the airflow and boost pressure setpoint (Fig. 5.5), which confirms the controller robustness.

\section{VI - CONCLUSIONAND FUTURE WORKS}

In this paper, we propose a systematic method to design a non square and robust control, which is applied here to the air path of a turbocharged Diesel engine. The computationally inexpensive control is thus obtained faster than the usual look-up table based control. Indeed, after frequency-domain system identification, a decentralized (3x2) CRONE control-system is designed by optimizing open-loop behaviors, while ensuring a good frequencydomain closed-loop specifications. Control performance of the proposed method has been demonstrated on a nonlinear model in co-simulation. Future works extend this paper to more complex technologies and apply it on our engine test bench. The global objectives to obtain the best compromise NOx/PM already stay our goal in future works, NOx emission will be checked by smoke-meter on the entire driving cycle, in order to evaluate the controller performances.

\section{VI - REFERENCES}

Alberer, D et al. (2010). "A virtual references design approach for diesel engine control optimization", Daniel Alberer, Markus Hirsch, Luigi del Re. Control Engineering Practice, Volume 18, Issue 11, Pages 12631271.

Åström, K.J. (1999). "Model uncertainty and robust control design”, Cosy Workshop - ESF Course, Valencia, Spain.

Chauvin, J. et al. (2006). "Experimental Motion Planning in Airpath Control for HCCI engine”, Jonathan Chauvin, Gilles Corde, Nicolas Petit and Pierre Rouchon, Proc. of the American Control Conference, Minneapolis, Minnesota, USA.

Chauvin, J. et al, (2008). "Motion planning for experimental airpath control of a diesel homogeneous charge compression ignition engine”, Jonathan Chauvin, Gilles Corde, Nicolas Petit, Pierre Rouchon, Control Engineering Practice

Volume 16, Issue 9, September 2008, Pages 1081-1091. 
Colin, G. et al. (2011). "Multi-SISO Robust Crone Design for the Air Path Control of a Diesel Engine", G. Colin, P. Lanusse, A. Louzimi, Y. Chamaillard, C. Deng, D. Nelson-Gruel, IFAC World Congress, Milan, Italy.

Dabo, M. et al. (2008). "NCGPC with dynamic extension applied to a Turbocharged Diesel Engine”, M. Dabo, N. Langlois, W. Respondek and H. Chafouk, Proceedings of the 17th IFAC World Congress, Seoul, Korea.

Dabo, M. et al. (2009). “ Dynamic Feedback Linearization applied to Asymptotic Tracking: generalization about the Turbocharged Diesel Engine outputs choice", Marcelin Dabo, Nicolas Langlois and Houcine Chafouk, American Control Conference, St. Louis, MO, USA.

Graybill, F.A. (1969). "Introduction to matrices with applications in statistics", Wadsworth.

Garcia-Nieto, S et al. (2008). "Nonlinear predictive control based on local networks for air management in diesel engine”, S. Garcia-Nieto, M. Martinez, X. Blasco, J. Sanchis, Control Engineering Practice 16 (2008) 1399. 1413

Jesse B, et al. (2006): "Sequential multisine signals for system identification of large structures" Jesse B. Hoagg, Seth L. Lacy, Vit Babuska, and Dennis S. Bernstein, Proceedings of the American Control Conference, Minneapolis, Minnesota, USA.

Kariwala, V. et al. (2003). "Block Relative Gain: Properties and Pairing Rules", Vinay Kariwala, J. Fraser Forbes, and Edward S. Meadows, Ind. Eng. Chem. Res., 2003, 42 (20), pp 4564-4574.

Kocher, L. et al. (2011). "Control-Oriented Modeling of Diesel Engine Gas Exchange”, Lyle Kocher, Ed Koeberlein, Karla Stricker, D. G. Van Alstine, Brandon Biller, and Gregory M. Shaver, American Control Conference, San Francisco, CA, USA

Lanusse, P. (1994): "De la commande CRONE de première génération à la commande CRONE de troisième generation", PhDThesis, Bordeaux I University, France.

Lanusse, P. et al. (2005). “Control Of Time-Delay Systems Using Robust Fractional-Order Control And Robust Smith Predictor Based Control", Lanusse P. and Oustaloup P., ASME International Design Engineering Technical Conferences and Computers and Information in Engineering Conference, Long Beach, California.

Larsen, M. et al. (2003). "Coordinated passivation designs”, Michael Larsen, Mrdjan Jankovi, Petar V. Kokotovi, Automatica, vol. 39, pp335 - 341

Leroy, T. et al. (2010). "Transient Burned Gas Rate Control on VVA equipped Diesel Engines", T. Leroy J. Chauvin N. Petit, 6th IFAC Symposium Advances in Automotive Control, Munich, Germany.

Michael, M and Walsh, P. (2000). "L'évolution des émissions des véhicules”, M. Michael P. Walsh, European Conference of ministers of Transport, Paris.

Murilo, A. et al. (2011). "Multivariable Control Strategy Based on a Parameterized NMPC for a Diesel Engine Air Path ” André Murilo, Mazen Alamir, Peter Ortner, 21st International Congress of Mechanical Engineering, Natal, RN, Brazil.

Nelson Gruel, D. et al. (2008). "Decentralized CRONE control of mxn multivariable system with time-delay”, D. Nelson Gruel, D., Lanusse, P. and Oustaloup, A., 3nd IFAC Workshop on "Fractional Differentiation and its Applications", Ankara, Turkey.

Nelson Gruel, D et al. (2009). "Robust control design for multivariable plants with time-delays", Nelson Gruel D., Lanusse P. and Oustaloup P., Chemical Engineering Journal - Elsevier, Vol. 146, Issue 3, pp 414-427.

Oustaloup, A. (1983). "Systèmes asservis linéaires d'ordre fractionnaire”, Masson, Paris.

Oustaloup, A. (1991). “La commande CRONE”, Hermes Editor, Paris.

Oustaloup A., Mathieu B. and Lanusse P. (1995): "The CRONE control of resonant plants: application to a flexible transmission", European Journal of Control, Vol. 1, n², pp. 113-121.

Oustaloup, A. et al, (2000). "The CRONE toolbox for Matlab”. Oustaloup A., Melchior P., Lanusse P., Cois O., Dancla F., IEEE International Symposium on Computer-Aided Control System Design", Anchorage, Alaska.

Oustaloup, A. et al, (2002). "Frequency synthesis of filter using the functions of Viète's roots", Oustaloup, A., Lanusse P. Levron F., IEEE Transactions on Automatic Control, Vol. 47, n5, pp. 837-841.

Oustaloup A. et al, (2008). "An overview of the CRONE approach in system analysis, modeling and identification, observation and control", Alain Oustaloup, Jocelyn Sabatier, Patrick Lanusse, Rachid Malti, Pierre Melchior, Xavier Moreau, Mathieu Moze, 17th IFAC World Congress, Seoul, Korea.

Stefanopoulou, A.G. et al. (2000). "Control of Variable Geometry Turbocharged Diesel Engines for Reduced Emission", A.G Stefanopoulou, I. Kolmanovsky, J.S Freudenberg. IEEE Transaction on Control Systems Technology, 8(4):733-745

Thomas, J. et al. (2008). "Frequency domain identification of synchronous machines by multisine excitation”, Thomas J. Vyncke, Frederik M.L.L. De Belie, René K. Boel, Jan A.A. Melkebeek, Yonghua Cheng and Philippe Lataire, 4th IEEE Benelux Young Researchers Symposium.

Wang, Y. et al. (2008). "Model-Based Quantitative Feedback Control of EGR Rate and Boost Pressure for Turbocharged Diesel Engines", Yue-Yun Wang, Ibrahim Haskara and Oded Yaniv, Proceedings of ACC, Seattle, Washington, USA.

Wang, Y et al. (2011). "Quantitative feedback design of air and boost pressure control system for turbocharged diesel engines", Yue-Yun Wang, Ibrahim Haskara, Oded Yaniv, Control Engineering Practice, Volume 19, Issue 6, Pages 626-637. 